\title{
A ESCOLA E OS DISCURSOS NÃO-DIDÁTICOS
}

\section{Desconsiderados ou mitificados, os discursos dos meios de comunicação povoam o cotidiano dos estudantes}

Há uma questão que tem inquietado os educadores: saber até onde os mecanismos discursivos tradicionalmente vinculados à aula continuam eficazes. A lousa, o excesso verbal, a fala quase sempre centrada no professor, ao lado de conteúdos, programas e currículos muitas vezes desatualizados ou respondendo mal às demandas colocadas por um mundo em rápida transformação, estariam contribuindo para o fracasso escolar e o desinteresse pela aprendizagem formal. Alunos dispersos e com dificuldades para acompanhar raciocínios mais complexos, problemas comportamentais e atitudinais indicariam alguns dos desajustes mais visíveis de causas com raízes fincadas no próprio modelo conceitual e operacional da escola presente.

Inevitável que diante deste quadro apareça freqüentemente a idéia de que existe concorrência desleal entre o andamento discursivo da escola e o dos meios de comunicação, postos de forma cada vez mais intensa na vida dos alunos. O colorido imagético da televisão, a velocidade do rádio, a animação do videogame configurariam padrões de apreensão da experiência que estariam em distonia com o ritmo quase que exclusivamente centrado no signo verbal, da sala de aula. O vigor atrativo dos signos icônicos e da interatividade (real ou aparente) para a qual tendem os veículos de comunicação levariam o aluno a se distanciar dos esquemas da contigüidade que estruturam os discursos verbais. A força da imagem e sua capacidade de presentificar e aproximar tornariam um tanto obsoletos certos esforços explicativos conforme processados tradicionalmente pela escola.

Usamos uma série de verbos no condicional por estarmos diante de uma matéria que necessita maior aprofundamento. A sagração pura e simples da imagem, dos apelos audiovisuais, ecoa sedutoramente, mas pode indicar, também, um momento em que as novas formas de se relacionar com a informação passam por reajustes. Natural, neste caso, que as tecnologias recentes, em seu amálgama de sons e imagens, pareçam ser a única luz a brilhar no fundo do poço.

De todo modo, a instituição escolar tem passado ao largo das questões afeitas às novas linguagens, em uma diametral oposição aos alunos que vivem em contato permanente com os apelos da televisão, do rádio, do cartaz publicitário, da história em quadrinhos, da música, do videogame ${ }^{1}$ etc.

\section{O AUTOR}

\section{Adílson Odair Citelli}

Professor Doutor do Departamento de Comunicações e Artes da Escola de Comunicações e Artes da USP. Especialista em Comunicação e Educação, autor dos livros O Texto Argumentativo, Linguagem e Persuasão e Romantismo, entre outros.

1. Ver neste número de Comunicação \& Educação artigo de Luciano Biagio Toriello, Videogame, escola e conto popular, acerca dos usos do videogame na escola. 


\section{A PRESENÇA MARCANTE DO RÁDIO}

Em nossa pesquisa realizada entre 1992 e 1995, sob o título A Circulação de Textos na Escola ${ }^{2}$ pudemos constatar os diferentes níveis de relação que os alunos mantêm com os veículos de massa e as novas tecnologias.

Para a consecução da referida pesquisa formulamos questionário com 49 perguntas que foram aplicadas em um universo de quase dois mil alunos, entre os anos de 1992 e 1993, junto às 15 escolas públicas municipais e estaduais da cidade de São Paulo, que vinham sendo observadas pelo Projeto A Circulação de Textos na Escola.

A aplicação do questionário foi dividida em duas fases. A primeira, feita em 1992, voltou-se às oitavas séries. A segunda, ocorrida no início de 1993, atingiu alunos das quartas e sextas séries que haviam sido observados quando cursavam terceiras e quintas. O que possibilitou manter-se o mesmo público de referência da pesquisa.

Em todas as escolas foram aplicados questionários nas séries citadas, por um período aproximado de duas horas por sala de aula. As questões eram abertas e requisitaram, de nossa parte, leitura cuidadosa para fins de tabulação, tendo em vista as singularidades e dificuldades envolvidas quer na faixa etária quer na diversidade sociocultural das crianças abrangidas pelo questionário.
Vejamos, a título de exemplo, o tipo de relação estabelecida entre os alunos e o rádio ${ }^{3}$.

\section{QUADRO I}

Pergunta: Você ouve rádio?

\begin{tabular}{lrrr}
\hline & 3: Série & 5 : Série & 8: Série \\
não & $4,48 \%$ & $1,38 \%$ & $1,12 \%$ \\
sim & $93,63 \%$ & $97,24 \%$ & $95,52 \%$ \\
\hline
\end{tabular}

Como se pode verificar, o rádio continua ocupando papel de grande importância no processo de comunicação.

Ainda que não se trate de comparar coisas diversas e com amplitudes técnicas e pragmáticas diferentes, o rádio está presente na vida de todos nós de forma, muitas vezes, ainda mais intensa do que o seu primo rico, a televisão ${ }^{4}$.

Em nossa pesquisa fizemos um levantamento das rádios e dos programas mais ouvidos pelos alunos. Aos interessados em obter detalhadamente tais dados é só consultar o citado questionário. Por ora, é suficiente lembrar que a frequiência dominante é a das FMs, assim como a música surge como gênero principal. O tipo de ritmo pouco varia: dance, rock, reggae e os sucessos passageiros, aqueles programados pela indústria do disco para durarem poucos meses.

2. Trabalho financiado pelo CNPq/FAPESP sob a coordenação dos professores Lígia Chiappini Moraes Leite (FFLCH/USP), Helena Nagamine Brandão (FFLCH/USP), Guaraciaba Micheletti (FFLCH/USP), João Wanderley Geraldi (IEL/UNICAMP) e Adílson Odair Citelli (ECA/USP). A pesquisa abrangeu um universo de 15 escolas públicas da cidade de São Paulo, envolvendo cerca de mil alunos das terceiras, quintas e oitavas séries. As escolas estavam localizadas nas quatro regiōes da cidade e apresentavam níveis socioeconômicos diferenciados. $\mathrm{O}$ trabalho contou, nesta fase, com a colaboraçâo de 15 pesquisadores entre iniciação-científica e aperfeiçoamento.

3. Há outros dados da pesquisa analisados no artigo A Circulação do Texto na Escola: mediaçôes dos veículos de massa. Comunicação \& Educação, n.1, set./dez., 1994. p. 21-26. (N.E.)

4. Ver sobre o assunto o artigo de BLOIS, Marlene M. O rádio nosso de cada dia. Comunicação \& Educação, n. 5, jan./abr., 1996. p. 13-21. (N.E.) 
Em dezembro de 1993, o jornal Folha de S. Paulo 5 apresentou o resultado de uma enquete para verificar os impactos do rádio na região da Grande São Paulo. Este trabalho, conquanto abrangendo um público amplo, chegou praticamente aos mesmos indicadores que apontamos em nossa pesquisa restrita aos alunos de terceiras, quintas e oitavas séries.

Com uma manchete reveladora Rádio bate audiencia de TV durante o dia, a Folha de S. Paulo aponta as emissoras mais ouvidas, sendo que as FMs têm 1.086,8 ouvintes/minuto, no horário entre $6 \mathrm{~h}$ e $19 \mathrm{~h}$, contra 627,8 das AMs. Com exceção da Rádio Globo AM, posta no pico da audiência, as cinco primeiras colocadas no ranking do mês de novembro de 1993 eram todas FMs. Entre elas estão algumas estações que já havíamos apontado em nosso trabalho como preferidas dos alunos: Transamérica, Jovem Pan e Rádio X.

$\mathrm{E}$, mais uma informação da pesquisa Folha relevante para as nossas conclusões. A pergunta acerca do meio de comunicação utilizado por mais tempo, quando remetida à parcela do público próxima ao do referido em nossa enquete, na faixa etária de 10 a 14 anos, produz respostas que dão ao rádio indicadores muito expressivos.

O reconhecimento da importância do veículo levou o Jornal ao seguinte comentário: "Engana-se quem imagina que hoje, sob o império da imagem, o rádio esteja agonizante. Com 70 anos de Brasil, um dos pioneiros da comunicação a distância ainda tem fôlego para seduzir mais o público que a televisão. Pesquisa do Datafolha indica que diariamente, entre $5 \mathrm{~h}$ e $18 \mathrm{~h}$, o rádio (AM ou FM) atrai uma média de 1,5 milhão de ouvintes por minuto na Grande São Paulo. Em período e local idênticos, a televisão conta com 700 mil telespectadores por minuto"6.

Estas informações interessam à escola e ao professor, pois se trata de reconhecer como os veículos de comunicação atuam na vida dos alunos. Ademais, é necessário apreender quais os padrões de cultura, as ofertas informativas, as referências estéticas e as sugestões ideológicas que derivam daqueles veículos. A partir deste reconhecimento, o trabalho pedagógico pode evoluir em pelo menos duas direções - para nos fixarmos apenas em possíveis exemplos envolvendo o rádio, objeto de nossa reflexão neste momento.

A primeira, discutir os mecanismos de uniformização e exclusão de produtos culturais. É possível verificar que as rádios FMs padronizam certos ritmos musicais oferecendo-os em abundância ao mesmo tempo em que sonegam outros.

As emissoras mais ouvidas pelos alunos repetem dois ou três ritmos dando-os como referências únicas; gera-se o mecanismo da estandardização. $\mathrm{E}$ isso deriva de gerenciamentos mercadológicos e de pressão das gravadoras e da indústria da música. Tais pressões envolvem, em geral, um vasto sistema de pagamento de cachês conhecido como "jabaculê" - aos programadores e apresentadores das rádios.

Não existe, neste caso, algo que se poderia chamar de mecanismo normal de mercado, de ritmos e sons que se afirmam em decorrência de sua maior ou menor qualidade. Estamos, ao contrário, no meio de um movimento em que os padrões de gosto podem ser simplesmente impostos por ajustes externos e que envolvem trocas comerciais: a gravadora paga e os produtores e disc-jóqueis colocam no ar. 
Vejamos dois dos quadros apresentados na pesquisa realizada pelo Datafolha da Folha de S. Paulo:

\section{QUADRO II}

Pergunta: Você diria que durante o dia passa mais tempo ouvindo rádio, vendo televisão, lendo revista ou lendo jornal?

\begin{tabular}{|c|c|c|c|c|c|c|c|c|c|c|c|c|}
\hline & \multicolumn{2}{|c|}{ SEXO } & \multicolumn{7}{|c|}{ IDADE } & \multicolumn{3}{|c|}{ ESCOLARIDADE } \\
\hline & Masc & Fem & 10 a 14 & 15 a 19 & 20 a 24 & 25 a 29 & 30 a 39 & 40 a 49 & $\begin{array}{c}50 \mathrm{ou} \\
\text { ou mais }\end{array}$ & $\begin{array}{c}\text { Até } \\
\text { 1: Grau }\end{array}$ & 2: Grau & 3: Grau \\
\hline Rádio & 36 & 53 & 39 & 60 & 56 & 49 & 44. & 41 & 33 & 45 & 49 & 37 \\
\hline TV & 40 & 31 & 52 & 27 & 28 & 31 & 33 & 32 & 41 & 39 & 30 & 26 \\
\hline Jornal & 13 & 5 & 2 & 4 & 7 & 11 & 12 & 13 & 10 & 6 & 11 & 23 \\
\hline Revista & 3 & 3 & 4 & 5 & 4 & 3 & 3 & 3 & 1 & 2 & 3 & 6 \\
\hline Outros & 8 & 8 & 3 & 3 & 5 & 7 & 8 & 11 & 15 & 8 & 6 & 8 \\
\hline
\end{tabular}

\section{QUADRO III}

Pergunta: Durante o dia você passa mais tempo ouvindo rádio, vendo televisão, lendo revista ou lendo jornal?

\begin{tabular}{|c|c|c|c|c|}
\hline Categorias & Total & Classes A/B & C & D/E* \\
\hline Rádio & 45 & 41 & 45 & 46 \\
\hline Televisão & 35 & 32 & 36 & 36 \\
\hline Jornal & 9 & 16 & 10 & 5 \\
\hline Revista & 3 & 4 & 3 & 3 \\
\hline Outras respostas & 8 & 6 & 7 & 9 \\
\hline
\end{tabular}

* Critério Abipeme (Associação Brasileira de Institutos de Pesquisa de Mercado)

É neste contexto que se deve proceder à discussão envolvendo de um lado a padronização e de outro a exclusão. Se cabe analisar com os alunos porque todos cantam as mesmas músicas é preciso saber qual a razão que impede sejam outras tantas cantadas ou tocadas.

A segunda direção envolve aproveitamentos pedagógicos do rádio derivados de objetivos propriamente de produção. Isto é, existem muitas possibilidades de tornar o aluno agente do veículo: elaboração de pro- gramas, realização de pequenas reportagens na área onde está localizada a escola, seleção de músicas, criação de novos produtos para serem transmitidos pelo rádio etc.

Como se vê, há trabalhos possíveis e simples de serem implementados pela escola e que permitem, inclusive, as práticas interdisciplinares. É pensar, por exemplo, como a criação de roteiros e argumentos para a feitura de programas pode vir a mobilizar professores de áreas como língua portuguesa, literatura, história, geografia, ciências etc.?

7. A revista Comunicação $\&$ Educação, através da seção Experiência, vem relatando importantes trabalhos do gênero desenvolvidos pelos próprios professores, em sala de aula. (N.E.) 
$\mathrm{O}$ encontro da primeira e da segunda direções produz a confluência dos mecanismos de análise e de produção. Vale dizer, ao realizar a leitura crítica do meio, o aluno pode, ao mesmo tempo, aprender a utilizar as potencialidades de um veículo que está tão presente em sua vida.

\section{QUADRO IV}

Pergunta: Quantas horas de rádio você ouve por dia?

\begin{tabular}{cccc}
\hline Horas & 3? Série & 5: Série & 8: Série \\
até 2 & $55,19 \%$ & $48,22 \%$ & $34,45 \%$ \\
2 a 4 & $19,34 \%$ & $22,76 \%$ & $21,85 \%$ \\
mais de 4 & $20,99 \%$ & $25,98 \%$ & $37,25 \%$ \\
\hline
\end{tabular}

O tempo disponível pelo aluno para a feitura de tarefas caracteristicamente escolares está se reduzindo sensivelmente. É verdade que, como declararam muitos dos entrevistados, várias atividades são realizadas ao mesmo tempo: ouve-se rádio e faz-se a lição de Matemática; assiste-se a um programa de televisão ou a um filme no videocassete - metade dos entrevistados possuem aparelho em casa - e escreve-se a redação de Português; joga-se videogame e preenche-se o questionário de Ciências. No entanto, e para lembrar o poeta, tal constatação pode fun- cionar como rima, mas definitivamente não é uma solução. Acerca desta concomitância foi perguntado aos alunos se realizavam outras atividades e de que tipo enquanto viam TV. A resposta foi a seguinte:

\section{QUADRO V}

Outras atividades

\begin{tabular}{llll}
\hline & 3? Série & $5^{\text {a }}$ Série & 8 ? Série \\
não & $44,81 \%$ & $50,57 \%$ & $57,14 \%$ \\
sim & $51,18 \%$ & $47,13 \%$ & $40,90 \%$ \\
\hline
\end{tabular}

\section{QUADRO VI}

Tipo de atividade

\begin{tabular}{lrrr}
\hline & $3^{\text {a }}$ Série & $5^{\text {a }}$ Série & 8 $^{\text {a Série }}$ \\
arruma casa & $6,37 \%$ & $6,67 \%$ & $1,68 \%$ \\
faz lição & $12,74 \%$ & $10,80 \%$ & $10,08 \%$ \\
outras & $32,08 \%$ & $30,34 \%$ & $30,25 \%$ \\
\hline
\end{tabular}

Os quadros acima, retirados a título exemplificativo dos 49 que formam a totalidade da enquete ${ }^{8}$, e que envolvem questões referentes à convivência do aluno com os meios de massa, confirmam o enunciado central deste artigo: as linguagens institucionalmente não-escolares ${ }^{9}$, aquelas que não

8. A pesquisa completa pode ser encontrada no relatório do Projeto A Circulação de Textos na Escola, Subprojeto três: A Circulação de Materiais não-Didáticos. Questionário acompanhado de análise de dados. Coordenação: Adílson Odair Citelli. Cópias com CNPq. FAPESP e bibliotecas da FFLCH (Faculdade de Filosofia, Letras e Ciências Humanas) e ECA (Escola de Comunicações e Artes) da USP. Por razōes metodológicas e pelas características da pesquisa realizada, a tabulação dos dados nem sempre fecha em $100 \%$. Participaram da aplicação dos questionários, assim como de sua posterior tabulação, análise qualitativa e feitura de artigos analíticos, Carla Diniz Lapenda, Eliana Nagamine, Fernando Valeriano Viana, José Luís Miranda e Kazuko Kojima Higuchi. Entraram na fase final da atividade as pesquisadoras Patrícia Christina Montezano e Ynaray Joana da Silva. Todos os envolvidos neste grupo de trabalho realizaram atividades de difusão dos resultados da enquete, discutindo com professores das escolas pesquisadas e em reuniōes mais amplas. Igualmente escreveram artigos analíticos decorrentes dos dados levantados pelos questionários, e que podem ser lidos no livro: CITELLI, Adílson Odair (org.). Aprender e ensinar com textos. v. 3. Aprender e ensinar com textos não-escolares. São Paulo: FFLCH-USP/CNPq/FAPESP/Pró-Reitoria de Pesquisa da USP, 1994. 147p. Este volume, com acréscimos de outros textos, será publicado pela Editora Cortez, de São Paulo. Ambos os volumes foram organizados por Adílson Odair Citelli.

9. Criamos esta categoria para indicar que na tensão das linguagens institucionalizadas - entre elas a da escola e a dos veículos de massa - existe forte concorrência. Caso, por exemplo, da luta discursiva que muitas vezes aponta contradições e quebras de interesses nas relações entre o judiciário, o legislativo ou o executivo. A escola, por vários motivos, possui uma ordem institucional muito fechada, daí permitir que o seu discurso seja dito apenas na circunscrição dessa ordem. A escola procura evitar, para se fazer uma afirmativa muito rápida e sumária, concorrência discursiva. 
costumam fazer parte do que se convencionou chamar de discurso pedagógico, exercem forte pressão sobre o universo escolar. E isto significa dizer que, a despeito de permanecerem confinadas no subterrâneo durante a aula, tais linguagens necessariamente continuam cutucando e incomodando, visto estarem presentes na vida do aluno.

Em síntese, expulsas pela porta da frente da escola e excluídas do discurso pedagógico institucionalizado, as linguagens da televisão, do vídeo, do outdoor, do rádio, do videogame retornam pela porta do fundo, cobrando o preço de terem sido ignoradas no ato formal da aula.

A questão, hoje, é a de verificar se a escola está disposta a reconhecer tal fato e que tipo de ações pretende desenvolver para criar novos parâmetros de relação entre as linguagens formais que circundam o discurso pedagógico e as linguagens produzidas pelos novos meios técnicos.

\section{OS DISCURSOS NÃO-ESCOLARES}

A escola, já tão cheia de problemas, tem a ela agregada, pelas próprias formas de produção e circulação contemporânea das informações e do conhecimento, mais uma questão. Trata-se de saber como refletir sobre e mesmo operar com as linguagens institucionalmente não-escolares, quer venham elas diretamente dos meios de massa quer sejam derivadas dos impactos das novas tecnologias - computador, sistemas interativos, comunicação a distância etc.

Cientes das implicações deste problema, várias instituições particulares de ensino de São Paulo, freqüentadas pelos filhos do país sem crise nem desemprego, estão buscando solucionar, à sua maneira, o problema. Tais escolas, motivadas muitas vezes por simples narcisismo tecnológico ou mesmo por razões mercadológicas, têm colocado seus alunos na rota da terceira onda (aquela caracterizada por Alvim Toffler como a da revolução industrial impulsionada pela informática), permitindo o acesso às novas linguagens e a convivência com outras estratégias de produção das informações.

É bom lembrar, conquanto de passagem, que esta investida modernizadora, por si só, não chega a garantir melhoria na qualidade do ensino proporcionado por aquelas instituições. Entre as salas dos microcomputadores das chamadas escolas de elite e os projetos pedagógicos consistentes e pactuados com a formação integral do aluno (processo que passa pelo espírito da reflexão, da pertinência dos conteúdos, dos objetivos sociabilizadores mais amplos), pode haver maior distância do que se imagina.

Antes de ser concebida à luz do simples marketing comercial-pedagógico, a questão do aprendizado e da relação com as novas linguagens deve estar vinculada a procedimentos educativos que não sejam apenas a nova face do estímulo ao espírito da concorrência e da maior capacitação para vencer as futuras dificuldades do vestibular e do mercado de trabalho. Educar, pelo menos em nosso entendimento, deve ser um ato de compromisso com a formação da cidadania.

A despeito deste último parágrafo, posto aqui como lembrete de uma discussão que necessita ser travada, mas que requisita outro espaço e outro momento, é necessário considerar que, no atual andamento da escola brasileira, verifica-se a continuidade dos velhos modelos concentradores e elitizados. Ou seja, prosseguimos na mesma marcha da exclusão que oferece à formação dos quadros dirigentes a possi- 
bilidade de acesso às inovações absorvidas pelas instituições de ponta. Aos demais fica destinada aquela que é chamada eufemisticamente de escola regular. Nesta, o processo continua sendo regido pelo que o citado professor de Geografia chamou de tecnologia avançada do giz e da lousa.

O problema no mundo contemporâneo é que a velocidade das transformações técnicas e o impacto das novas linguagens não permite a existência de uma acomodação a sistemas únicos de produção e recepção de sentidos. Se os alunos estão dizendo, como verificado em nossa pesquisa, que o videocassete, $\mathrm{o}$ anúncio publicitário, a música estão presentes com grande força em suas vidas, trata-se, evidentemente, de adequar estratégias pedagógicas que levem ao reconhecimento das formas constitutivas daquelas linguagens, em suas dimensões formais, estéticas, ideológicas e pragmáticas.

Ocorre que trazer para o universo pedagógico a linguagem com a qual os alunos convivem diariamente implica superar uma série de obstáculos. Alguns são de natureza técnica - a precariedade dos equipamentos existentes nas escolas -, outros decorrem da quase inexistência de políticas voltadas à formação continuada do professor - que necessita aprender a trabalhar com as estruturas formadoras daquelas linguagens e, por último, os que resultam do puro preconceito.
Eliana Nagamine reconhece que para muitos educadores a questão da mídia já se colocou como um problema a ser amplamente considerado. No entanto, lembra a Autora, a instituição escolar " “(...) não vê o campo da comunicação de massa como objeto de reflexão. Assim, partindo-se do pressuposto de que a interação do aluno com as linguagens da mídia produz modos diferenciados de construção do imaginário, a escola estaria incorrendo num profundo anacronismo, na medida em que pouco ou nada discute sobre determinados valores éticos, estéticos e ideológicos apresentados pelos meios de comunicação de massa, tampouco o modo de construção de sua linguagem, nem as possíveis mudanças comportamentais provocadas pelo bombardeio dos produtos mediáticos"10.

Noutros termos, conquanto exista da parte dos docentes sensibilidade para o problema, a instituição escolar ainda não apresentou vontade de agendar em seus projetos e programas uma ampla discussão sobre como enfrentar a presença dos veículos de massa no universo dos alunos, sequer como definir maneiras de se relacionar com as novas formas de produção do conhecimento e da informação ${ }^{11}$.

Parece, portanto, cada vez mais pertinente trazer para a escola as questões sugeridas pelas novas linguagens, a fim de que se possa construir uma nova educação humanista, aquela preparada para não apenas ler e conviver com as mensagens de massa e

10. Televisão, publicidade e escola. In: Aprender e ensinar com textos. Aprender e ensinar com textos não-escolares. $O p$. cit. p.25. Veja-se, ainda, SFEZ, Lucien. Crítica da comunicação. São Paulo: Loyola, 1994. ADORNO. Theodor e HORKHEIMER, Max. A induistria cultural: o lluminismo como mistificação das massas. In: LIMA, Luís Costa (org.). Teoria da cultura de massa. Rio de Janeiro: Paz e Terra, 1982. LIPOVETSKY, G. A era do vazio: ensaios sobre o individualismo contemporâneo. Lisboa: Relógio d'água, [s.d.]

11. Ver: BALDIN, Pierre; KOULOUMDJIAM, Marie France. Os novos modos de compreender - a geração do audiovisual e do computador. São Paulo: Paulinas, 1989. LÉVY. Pierre. As tecnologias da inteligência e o futuro do pensamento na era da informática. Rio de Janeiro: Editora 34, 1994. GUILLAUME, Marc. La signification sociale des nouvelles telétéchnologies. Comunicação \& Política. São Paulo: Oito de Março. v. 9 (2.3 e 4), jun./dez.. 1989. p.79-86. 
as tecnologias, mas fazê-lo em uma perspectiva crítica. Daí ser necessário rever o próprio conceito de leitura com o qual tradicionalmente os professores de língua têm operado e repensar o encontro dos signos em sua multiplicidade e capacidade de produzir novas formas de significação.

Neste contexto, torna-se imperioso levar para o espaço de reflexão dos docentes que atuam nas escolas de nível médio as pesquisas em andamento sobre a leitura crítica dos meios de massa. Elas apontam uma série de caminhos que permitem tratar de forma não reificada os impactos das novas linguagens e das novas tecnologias no universo do aluno.

Resumo: Através de resultados do Projeto de Pesquisa A circulação de textos na escola, o autor destaca a importância dos discursos não-didáticos, principalmente os dos meios de comunicação e sua penetração no universo do estudante, sendo, portanto, imperioso tratá-los na instituição educacional. Propõe que os professores tenham acesso às pesquisas sobre leitura crítica dos meios e recebam orientaçāo de como trabalhar essas novas linguagens no espaço pedagógico.

Palavras-chave: Discursos nāo-didáticos, Escola, Rádio, Televisão, Meios de comunicação
Os trabalhos de leitura crítica ${ }^{12}$ têm se voltado ora a verificar a natureza estrutural das mensagens contemporâneas veiculadas pelas diferentes mídias ora a indagar acerca dos impactos públicos gerados por tais mensagens. A ser processado com a radicalidade necessária, o exercício da análise crítica pode representar importante referência para o trabalho pedagógico, agilizando-o, colocando-o em sintonia com as mudanças que estão marcando os modos de ver, sentir e de pensar dos alunos. Noutros termos, trata-se de incorporar a pluralidade dos signos a um campo - o da escola - onde seja possível discutir e questionar o que muitas vezes tem sido ou simplesmente esquecido e sonegado ou mesmo apresentado de forma a esconder mecanismos de pura mistificação.

\begin{abstract}
Through the results of the Research Project Circulation of Texts in School, the author points out the importance of non-didactic discourse, mainly that which is conveyed through the media, and its penetration in the student's universe. It is therefore imperative to deal with it in the education institution. The author suggests that teachers be acquainted with the available studies on critical interpretation of the information conveyed by media and receive orientation on how to work upon these new languages in the pedagogical space.
\end{abstract}

Key-words: non-didactic discourse, school, radio, television, media

12. Existe já um bom número de trabalhos dedicados ao problema. Recomenda-se aos interessados a leitura dos vários números desta Revista Comunicação \& Educação. O CENECA (Centro de Indagación y Expressión Cultural y Artística), sediado no Chile, produziu, em colaboração com a UNESCO e o UNICEF, material que contém um diagnóstico da situação latino-americana. quanto às reflexões e implementações da educação para os meios. Na obra são encontradas desde colaborações de especialistas no assunto até levantamentos dos países que já possuem programas de educação e leitura crítica dos meios de massa. Ver: Educación para la comunicación. Manual latinoamericano de educación para los medios de comunicación. Chile: CENECA/UNESCO, 1992. O Núcleo de Comunicação e Educação, do Departamento de Comunicaçōes e Artes, da ECA/USP, elaborou, sob coordenação do Prof. Dr. Ismar de Oliveira Soares, bibliografia especializada nas interfaces comunicação/educação/leitura crítica. 